\title{
Early Childhood Education Centers' Reported Readiness to Implement the Updated Child and Adult Care Food Program Meal Pattern Standards in the United States, 2017
}

Jamie F. Chriqui, PhD, MHS, ${ }^{1,2}$ Julien Leider, MA, and Rebecca M. Schermbeck, MPH, MS, RD ${ }^{2}$

\section{Abstract}

Background: The Child and Adult Care Food Program (CACFP) serves nutritious meals/snacks to $>3.6$ million children in early childhood education (ECE) centers. This study provides a nationwide assessment of nonhome-based CACFP-participating ECE centers' awareness of and reported readiness for implementing updated CACFP standards/best practices that took effect October 1, 2017.

Methods: A national frame of 38,760 centers serving children ages 0-5 was developed. A web-based survey of 5483 sampled centers, stratified by census division, was conducted between August 22 and September 30, 2017. One thousand three hundred fortythree centers $(25 \%)$ located in 47 states and the District of Columbia responded. Surveys were primarily completed by center directors/assistant directors (71\%). Nonresponse adjusted multivariate regressions were conducted, controlling for center/zip codelevel characteristics.

Results: The majority of centers reported being "very" familiar with the updated standards and met specific standards/best practices. Centers that reported being "somewhat" (vs. "very") familiar with the standards were less prepared and likely to have begun implementation and more likely to need additional time, money, and staff. Centers that reported being "not"/"somewhat" familiar (vs. "very") with the updated standards were also less likely to meet specific standards/best practices. Center preparedness and standards/best practices varied by weekly rates/fees charged. Centers in the West (vs. South) were more likely to report meeting sugary cereal standards and fruits and vegetables as a snack component best practice.

Conclusions: While most centers reported familiarity with and were prepared to implement the updated CACFP standards, readiness is not universal. Technical assistance and training should ensure that all centers are trained on the updated standards.

Keywords: CACFP; early child care; nutrition; regulation

\section{Introduction}

$\mathbf{M}$ ore than 3.6 million children are enrolled in early childhood education (ECE) centers that participate in the Child and Adult Care Food Program (CACFP), which provides nutritious meals and snacks to participants. ${ }^{1,2}$ CACFP is open to child care providers who serve children from families that meet the U.S. Department of Agriculture's (USDA's) income eligibility guidelines for free and reduced-price meals. ${ }^{3}$ Nutrition standards for the program are issued by the USDA. Effective October 1, 2017, updated
CACFP meal pattern standards took effect. The updated standards required CACFP-participating child care centers to serve more whole grains, a wider variety of fruits and vegetables $(\mathrm{F} \& \mathrm{~V})$, and less solid fats and added sugars. ${ }^{1,4}$

Strengthening the meal pattern standards for centers serving children younger than 5 years was considered important because this is an influential age for food preference development. ${ }^{5}$ USDA provided a 1-year transition period for centers making a "good faith" effort to comply with the standards. ${ }^{6}$ Before the updated standards, researchers found CACFP-participating centers in certain

'Division of Health Policy and Administration, School of Public Health, University of Illinois at Chicago, Chicago, IL.

${ }^{2}$ Institute for Health Research and Policy, University of Illinois at Chicago, Chicago, IL. 
states to have stricter nutrition practices or to be more compliant with standards than non-CACFP-participating sites, to have more supportive nutrition practices, and to report better child health outcomes. ${ }^{7-17}$

To date, only a few studies have assessed readiness for implementing and/or compliance with state and/or federal ECE nutrition standards. Research conducted in California found that 2 months after a new state-level beverage policy for child care centers was implemented, more than $60 \%$ of sampled sites (CACFP sites, $67.3 \%$ and non-CACFP sites, $42.2 \%$ ) were aware of the policy. Only $25 \%$ of sampled sites were in full compliance, with CACFP sites significantly more likely to comply than non-CACFP sites. Compliance was attributed to policy awareness and information being provided to families. ${ }^{16}$

Also, two studies examined readiness for implementing and/or compliance with the updated CACFP standards. Schwartz et al. (2015) assessed lunches through direct observation in 38 CACFP-participating Connecticut child care sites and compared the current (at that time) CACFP requirements with the 2011 Institute of Medicine recommendations and USDA's January 2015 proposed CACFP rule. They found CACFP-participating child care sites generally complied with the proposed rule amounts for each meal component to be served at lunch. ${ }^{18}$ Recently, Dave and Cullen (2018) assessed the 2016 menus of nine CACFP-participating child care sites in Texas to determine adherence to the updated CACFP standards. They found that sites fully met $50 \%$ of updated meal pattern requirements and partially or fully met $60 \%$ of the best practices. ${ }^{19}$

The current study builds on this prior work with a nationwide sample. The goal of the present study was to assess nonhome-based CACFP-participating ECE centers' reported readiness for implementing the updated CACFP meal pattern standards. For the purposes of this study, "readiness" was viewed from the lens of the theoretical literature. For example, in the Stages of Change Transtheoretical Model, the preparation (readiness) stage is the stage at which people have a plan, are ready to make changes within the next month, and/or have already been making changes over the past year, and it immediately precedes the action stage. $^{20}$

While a literature around nutrition standards and practices in ECE settings and CACFP-participating centers, specifically, has been emerging, there has not been a nationwide study of such practices or an assessment of where centers' practices stand nationally relative to the USDA's updated standards; this study aimed to help fill this gap.

\section{Methods}

\section{Sample Frame}

No national sample frame of CACFP ECE centers existed, and so, one was developed by obtaining lists from each state CACFP agency between September 2016 and March 2017. Open record requests were required for nine states' lists. Lists were obtained for all states and the
District of Columbia (DC) except for Maine (no response from the state) and Louisiana (only sponsor information provided). The final frame included 38,760 eligible, nonhome-based, CACFP-participating centers (henceforth referred to as "Centers") that served children ages 0-5 years in 48 states and DC.

Home-based centers were excluded from the sample because of the relatively low number of children attending child care homes that participate in the CACFP $(756,947$ children in fiscal year 2017), ${ }^{2}$ and state and federal child care registries are only able to document about $10 \%$ of paid home-based centers making it difficult to develop a reliable sample from this center type. ${ }^{21}$

\section{Sample Selection and Verification}

To obtain a nationally representative sample, we randomly sampled Centers within each of the nine census divisions using stratified sampling with proportional allocation. USDA's counts of CACFP ECE centers by state were used to compute census division shares. ${ }^{22}$ Although USDA's list included all CACFP providers (including home-based and adult care) and, unlike our frame, was not restricted to traditional child care centers serving children ages $0-5$, the numbers in our frame and USDA's list provided similar division shares. Given the possibility that some ineligible centers remained in our frame, the USDA list was chosen as the most reliable source for computing proportional division shares. Ultimately, 5604 of the 38,760 ECE centers included in our frame were sampled.

Between January and August 2017, we attempted to verify the state-provided information for the sampled centers via Internet research or telephone calls. Of the originally sampled centers, $19 \%$ were ineligible or closed and were replaced, while we obtained new or updated contact information for about half.

\section{Survey Development and Administration}

A primarily closed-ended survey (see Supplementary Appendix) was developed to align with the updated standards and best practices ${ }^{4}$ and to draw on prior relevant CACFP and/or ECE surveys. ${ }^{12,23-26}$ Consultants with expertise on early childhood nutrition and CACFP also provided input to the survey content. Cognitive interviews were conducted with seven center directors (or their designees) located in Illinois and Florida (where two of the study authors reside) to test the survey wording and design. ${ }^{27,28}$ The cognitive interviews led to a number of survey changes (see Supplementary Appendix for an explanation of changes and the rationale; Supplementary Data are available online at www.liebertpub.com/chi).

Food and beverages $(F \& B)$ included in the survey were selected based on the cognitive interview conversations to reflect those items most commonly offered/served/consumed at the child care centers. Unfortunately, a vegetable selection from the peas/legumes group was inadvertently left off the survey. The final survey was programmed and 
administered as a web-based survey using a Research Electronic Data Capture (REDCap) system. ${ }^{29}$ The survey took 10-20 minutes to complete. All survey respondents were provided an opportunity to earn 1 of $20 \$ 150$ Amazon electronic gift cards for use by their center. UIC's Institutional Review Board granted a claim of exemption for the study (protocol \#2017-0549).

The survey was fielded between August 22 and September 30, 2017 (before the October 1 effective date for the updated standards), with reminder e-mails sent weekly. Invitations were sent to center directors/assistant directors or the sponsor, and survey instructions asked that the people responsible for center CACFP participation and $\mathrm{F} \& \mathrm{~B}$ provision, respectively, complete the corresponding survey sections. The e-mail invitation provided centers with an opportunity to complete the survey by phone (four sites chose this option) and we mailed a copy of the invitation letter to 681 centers where e-mail addresses could not be obtained. On fielding the survey, additional centers were deemed ineligible, resulting in a final sample of 5483 eligible centers.

Completed surveys were obtained from 1343 centers (25\% response rate using the American Association of Public Opinion Research Outcome Rate Calculator ${ }^{30}$ ) located in 47 states and DC. An additional 142 (3\%) surveys were partially completed but were not used. Invitations were suspended to 297 (5\%) centers located in areas affected by Hurricanes Harvey and Irma. Our final completed response rate was comparable with that of prior CACFP- or ECE nutrition-related studies that used similar survey administration methods ${ }^{12,16,31-33}$ and is consistent with recent literature on low web-based survey response rates, ${ }^{34,35}$ particularly for hard-to-reach populations. The survey was primarily completed by center directors/assistant directors $(71 \%)$.

The survey data were weighted to account for nonresponse using propensity score methods. Zip code-level characteristics for each center were obtained from the American Community Survey 2011-2015 5-year estimates $^{36}$ and included in a logistic regression model interacted with the census division to estimate the probability of nonresponse for each site. Nonresponse weights were computed within deciles of the estimated nonresponse probabilities using the inverse of the response rate. Weighted data on zip code-level community characteristics from the responding centers were comparable with characteristics of the full sample, as shown in Supplementary Table S1.

\section{Analyses}

All analyses were conducted using STATA/SE 13.1, accounting for the survey design and weights. Descriptive statistics were computed for the center characteristics and outcome measures (Tables 1 and 2). Multivariate logistic regressions were used to assess measures of reported implementation readiness (Table 3), and to assess $\mathrm{F} \& \mathrm{~B}$ practices meeting required standards and best practices

\begin{tabular}{|c|c|c|}
\hline Characteristic & $\begin{array}{l}\% \text { or } \\
\text { Mean }\end{array}$ & $95 \% \mathrm{Cl}$ \\
\hline Corporate owned & 30.11 & 27.39-32.97 \\
\hline Head Start/Early Head Start & 34.09 & $31.24-37.06$ \\
\hline Food program sponsored & 38.93 & $35.98-41.96$ \\
\hline State-enhanced CACFP standards & 55.16 & $52.30-57.99$ \\
\hline Compliance checks conducted by state & 53.93 & $50.86-56.97$ \\
\hline \multicolumn{3}{|l|}{ Length center participated in CACFP } \\
\hline$<10$ Years & 38.12 & $35.04-41.30$ \\
\hline 10+ Years & 61.88 & $58.70-64.96$ \\
\hline \multicolumn{3}{|l|}{ Familiarity with revised standards } \\
\hline Not at all/I don't know & 7.67 & $6.11-9.60$ \\
\hline Somewhat & 28.14 & $25.47-30.98$ \\
\hline Very much & 64.19 & $61.17-67.09$ \\
\hline \multicolumn{3}{|l|}{ No. of staff employed at center } \\
\hline I-10 Employees & 34.34 & $31.49-37.32$ \\
\hline I I-20 Employees & 38.02 & $35.10-41.03$ \\
\hline 21-30 Employees & 15.63 & $13.50-18.02$ \\
\hline$\geq 31$ Employees & 12.01 & $10.20-14.09$ \\
\hline \multicolumn{3}{|l|}{ Total enrollment capacity } \\
\hline I-25 Children & 7.30 & $5.88-9.03$ \\
\hline 26-50 Children & 17.15 & $14.97-19.57$ \\
\hline 5I-100 Children & 39.76 & $36.76-42.83$ \\
\hline 101-499 Children & 35.79 & $32.92-38.77$ \\
\hline \multicolumn{3}{|l|}{ Weekly rate for 2-5-year-old children } \\
\hline Free/no cost OR state subsidized & 20.42 & 18.09-22.97 \\
\hline$\$ 1-\$ 100.99$ & 14.12 & $\mid 1.96-16.61$ \\
\hline$\$ 101-\$ 200.99$ & 49.03 & $45.96-52.12$ \\
\hline$\geq \$ 201$ & 16.42 & $14.48-18.57$ \\
\hline \multicolumn{3}{|l|}{ Majority race (zip code level) } \\
\hline Majority $(\geq 50 \%)$ non-Hispanic white & 56.17 & $53.07-59.23$ \\
\hline Majority ( $\geq 50 \%)$ non-Hispanic black & $|2.6|$ & $10.45-15.13$ \\
\hline Majority ( $\geq 50 \%)$ Hispanic & 14.64 & $12.52-17.05$ \\
\hline Mixed & 16.58 & $14.28-19.17$ \\
\hline \% Urban (zip code level) & 82.72 & $81.10-84.34$ \\
\hline \multicolumn{3}{|l|}{ Census region } \\
\hline Northeast & 17.50 & $16.31-18.75$ \\
\hline Midwest & 18.63 & $17.74-19.54$ \\
\hline South & 42.21 & $40.92-43.51$ \\
\hline West & 21.67 & $20.69-22.68$ \\
\hline
\end{tabular}

$N=1343$ CACFP Child Day Care Centers; $n=|| 190-\mid 343$ due to missing data (and a skip pattern for weekly rate that only affected one observation).

CACFP, Child and Adult Care Food Program. 
Table 2. Readiness and Food and Beverage Practice Characteristics (Weighted) Characteristic

Readiness outcomes (of those reporting being "somewhat" or "very familiar") with the standards

Very prepared to make changes $\%$ or Mean $95 \% \mathrm{Cl}$

Began implementing standards: very much

Additional time needed to implement

Additional \$ needed to implement

Additional staff needed to implement

Staff opposition to revised standards

Food and beverage practices

Meets beverage standards/best practices ${ }^{\mathrm{a}}$ (Std./BP)

24.61

$21.94-27.48$

$<6 \mathrm{~g}$ sugar per dry ounce of cereal (Std.)

86.31

$83.91-88.41$

Only plain/unflavored or no yogurt (Std.)

69.90

67.00-72.64

$100 \%$ whole grains (BP)

Fruit or vegetable as component of snack at least once a day (BP)

Dark green vegetables at least once a week (BP)

Red/orange vegetables at least once a week (BP)

Starchy vegetables at least once a week (BP)

Other vegetables at least once a week (BP)

$N=1343$ CACFP Child Day Care Centers. The number of cases included varied by question: $n=|24|-\mid 244$ for readiness outcomes (which were only asked of 1245 centers that reported being "somewhat" or "very much" familiar with the standards) and $n=1295-1334$ for food and beverage practices (which were asked of 1340 centers, excluding 3 centers that did not provide meals/snacks or did not serve 2-5-year olds). ${ }^{a}$ Includes fresh water availability, never serving flavored milk, serving 100\% juice less than twice a day, and never serving fruit drinks or regular soda.

CACFP, Child and Adult Care Food Program; Std., standard; BP, best practice.

(Table 4). All regression models controlled for center and community characteristics, as shown in Table 1, including center-level characteristics obtained from Section A of the survey, whether the state had enhanced CACFP nutrition standards (before the USDA update), ${ }^{37}$ census region, and ZIP code-level race/ethnicity and urbanicity obtained from the Census Bureau. ${ }^{36,38,39}$

Missing center-level characteristic data limited the maximum number of cases in regression models to 1102 . Questions about implementation readiness (Table 3) were only asked where respondents stated being "somewhat" or "very much" familiar with the revised standards. That skip pattern and additional missing data on specific outcomes left a range of 1041-1098 cases in the analyses presented herein.

\section{Results}

Weighted characteristics of the centers are presented in Table 1. Table 2 presents descriptive data on centers' reported readiness for implementing the updated standards. The majority of centers reported being "very" prepared to make changes, to have "very much" begun implementing the standards, and needing at least "some" additional time and money to implement the standards. Half of the centers reported needing at least "some" additional staff for implementation.

Most of the centers reported meeting the beverage standards/best practices for fresh water availability, never serving flavored milk, serving $100 \%$ juice $<2$ times/day, and never serving fruit drinks or regular soda. The majority of centers reported meeting the standards for only serving cereals with $<6 \mathrm{~g}$ of sugar/dry ounce and the best practice for serving $100 \%$ whole grains; however, only $33 \%$ of the centers reported serving only plain/unflavored yogurt or no yogurt (we were unable to assess the sugar content of yogurt). In terms of best practices, the majority of centers reported serving a fruit or vegetable $(\mathrm{F} / \mathrm{V})$ as a component of a snack at least 1 time/day and served at least one serving each of dark green leafy vegetables, red or orange vegetables, starchy vegetables, and other vegetables at least 1 time/week. Nearly three-quarters of the centers reported meeting the best practices for serving processed meats $<1$ time/week. 


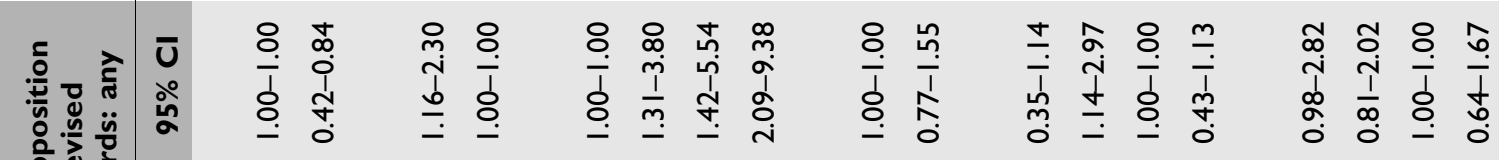

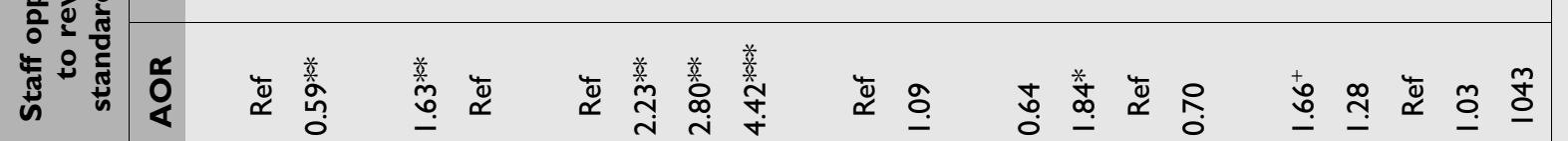

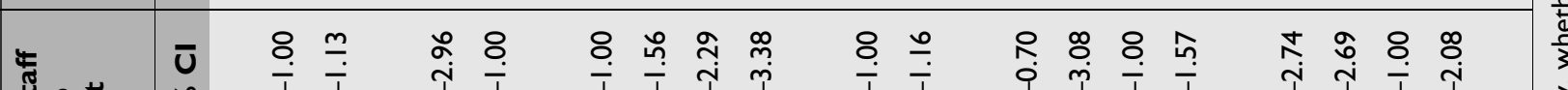

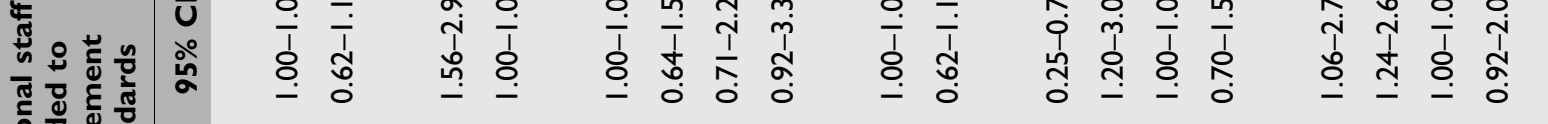

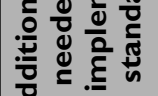

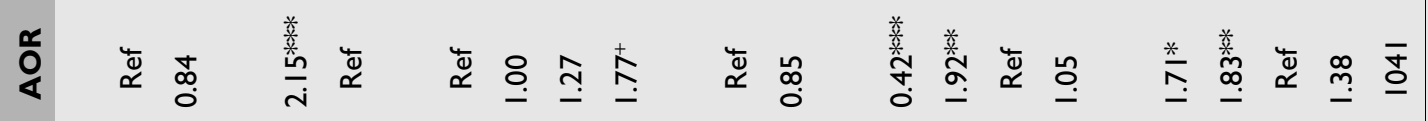

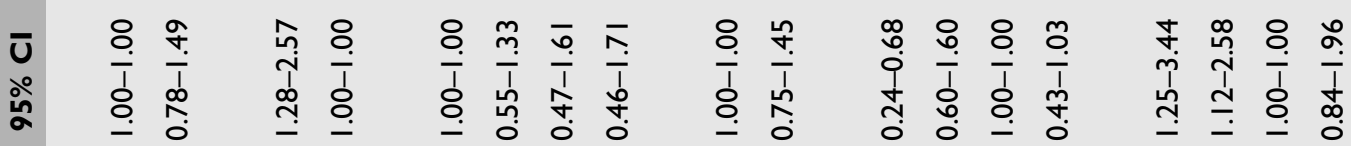

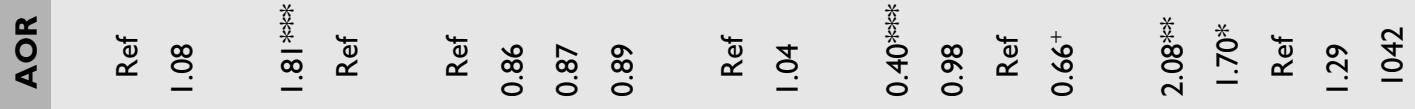

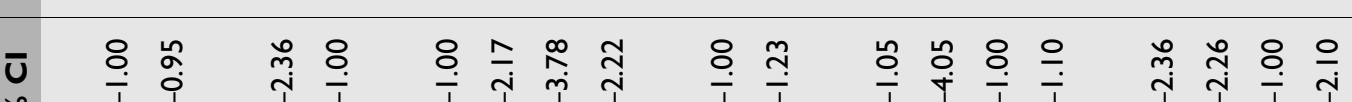

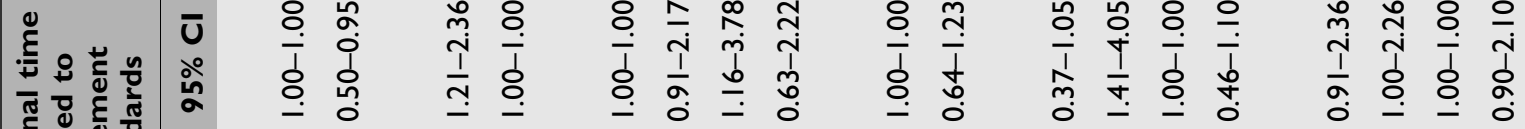

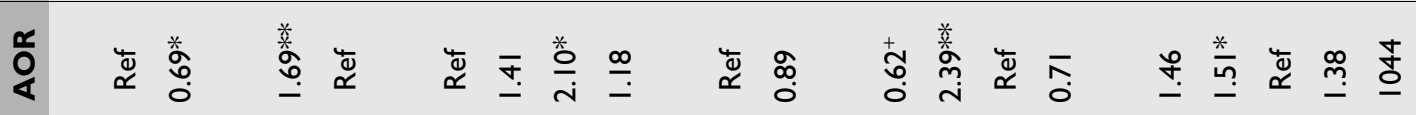

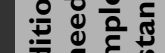

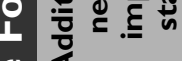

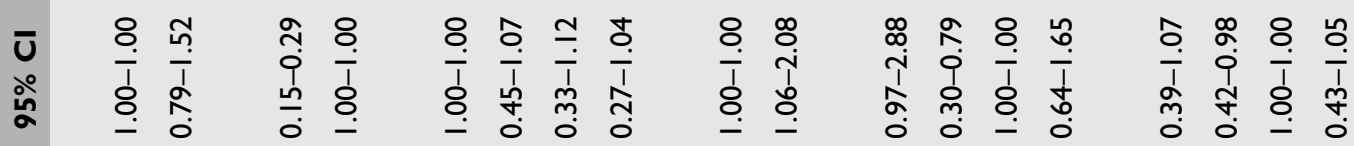

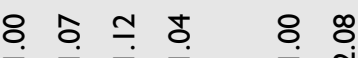
कำ

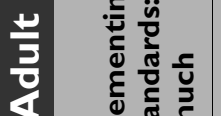

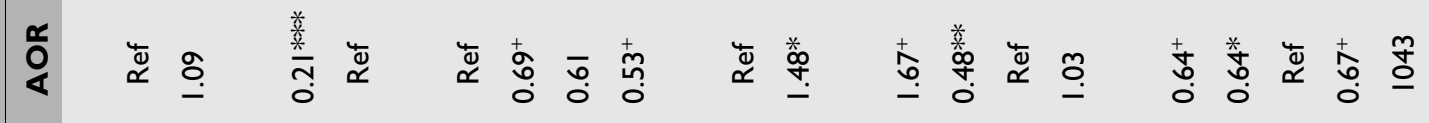

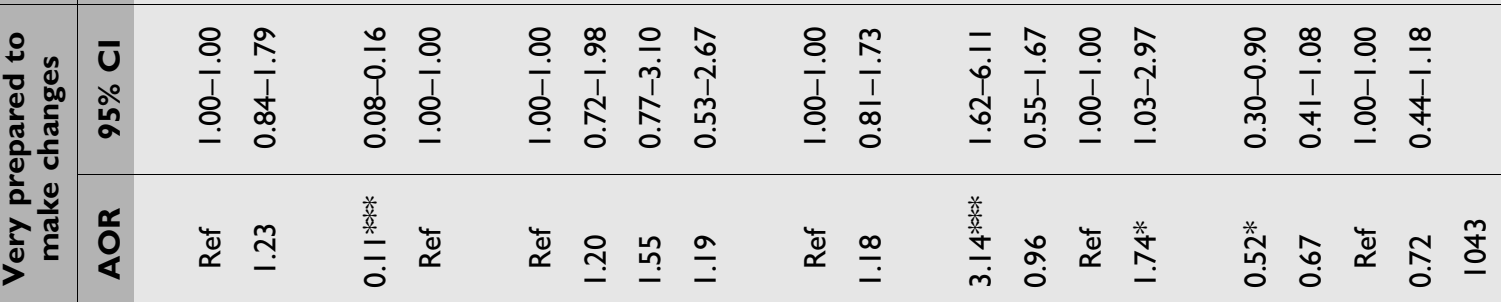

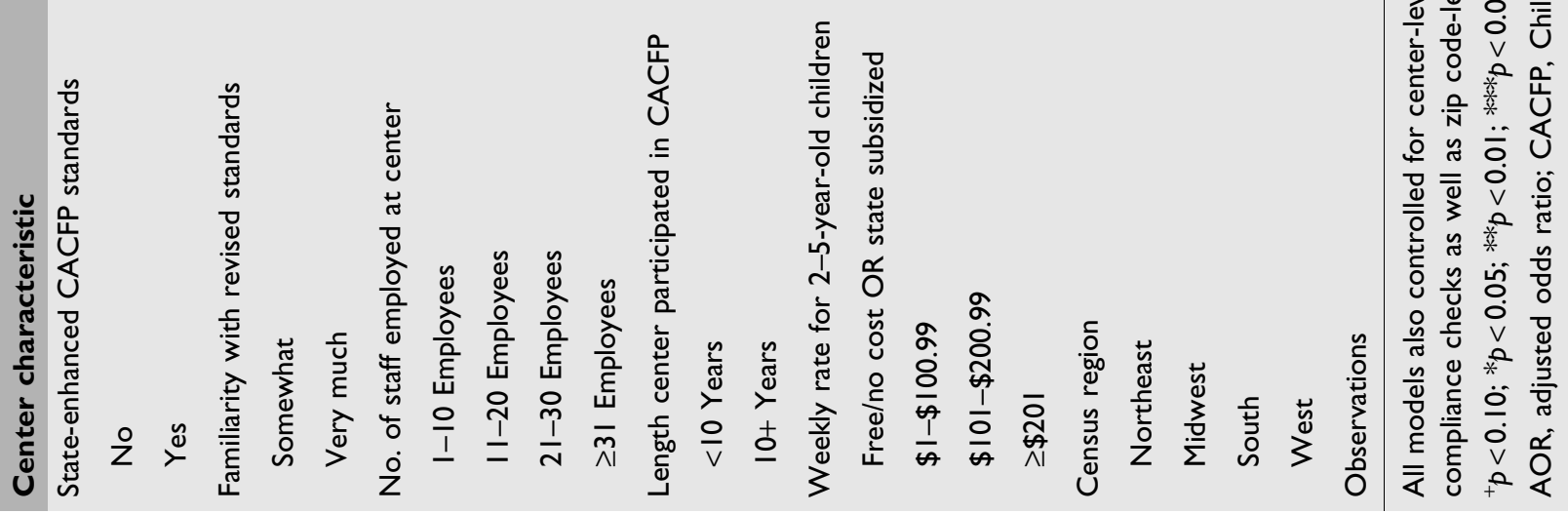




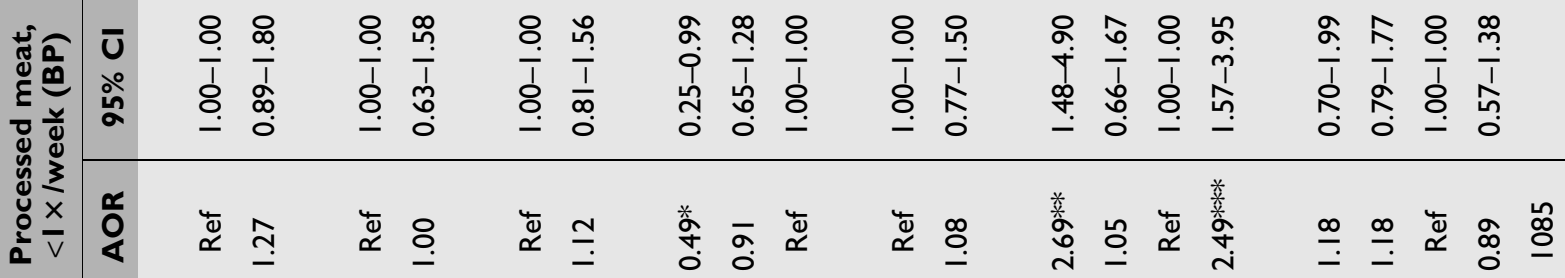
縭

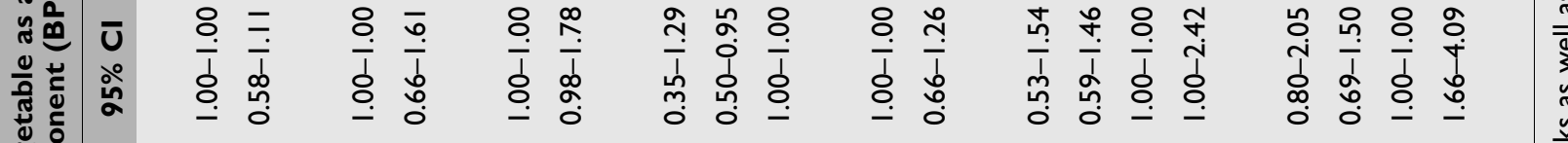

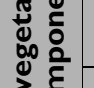

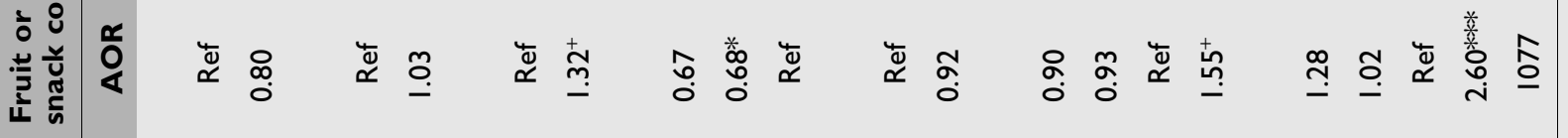

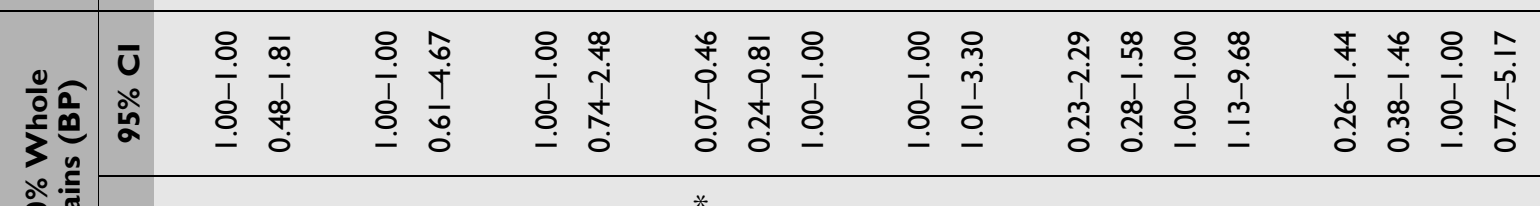

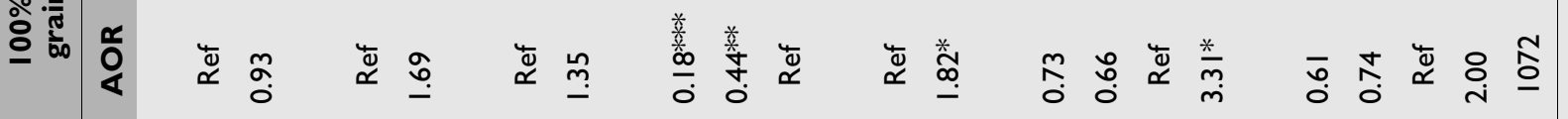

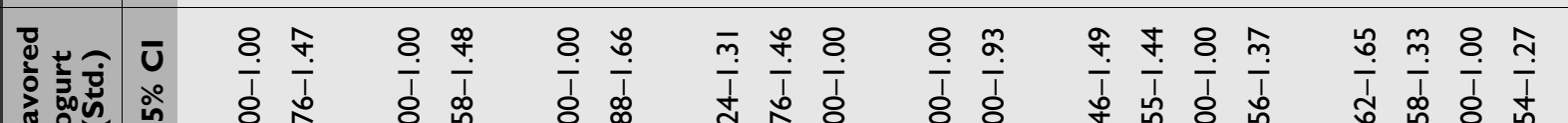

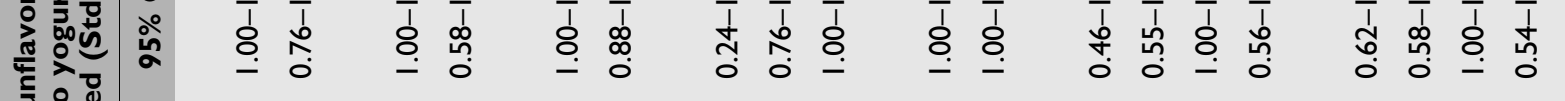

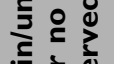

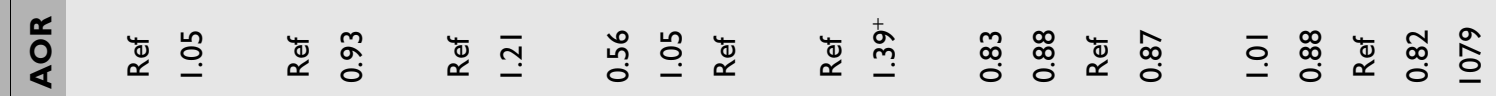

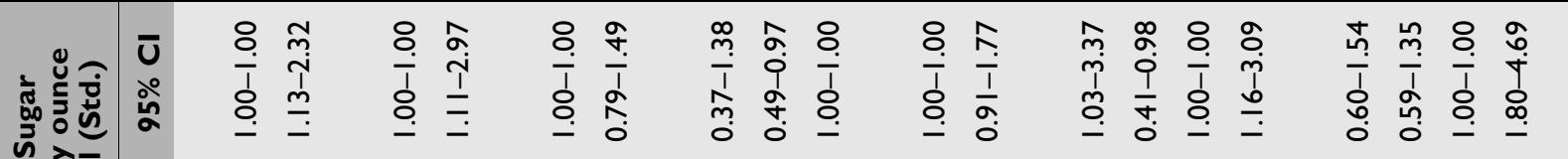
ด 要要 $\frac{2}{2}$

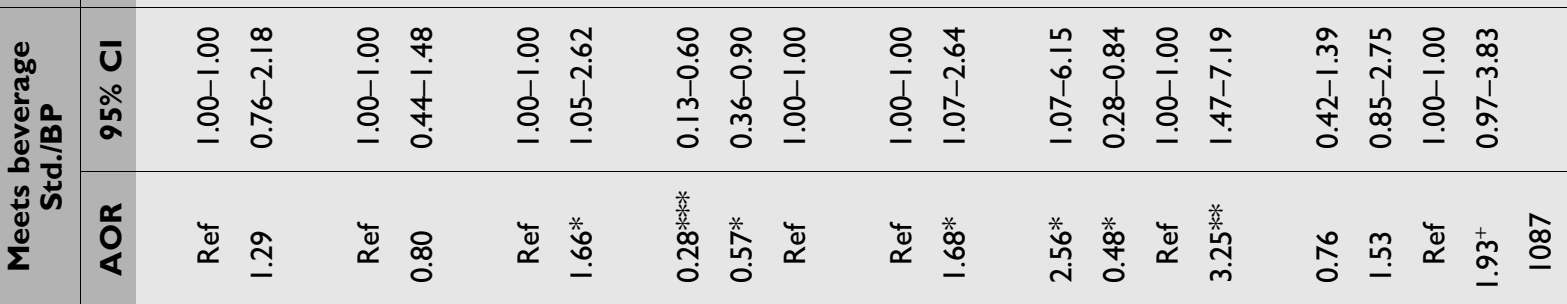

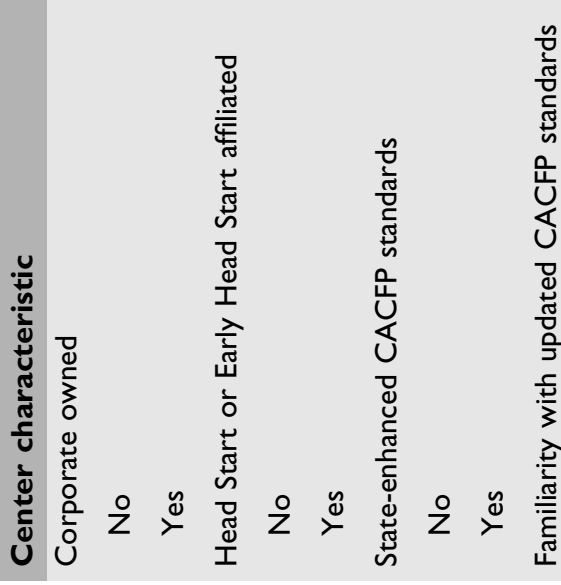

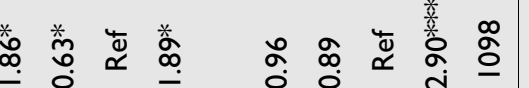

sos

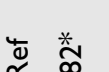

sis

कृ 


\section{Factors Influencing Readiness to Implement}

\section{the Updated Standards}

Characteristics associated with center-reported readiness to implement the updated standards are presented in Table 3. Centers located in states with enhanced CACFP standards were less likely to report needing additional time to implement or facing staff opposition to the standards. Centers that were only "somewhat" as opposed to "very" familiar with the updated standards were less likely to report being "very" prepared to make changes and to have "very much" begun implementation; and were more likely to report needing additional time, money, or staff to implement the standards and to face staff opposition. Centers with more staff ( $>10$ employees) were more likely to report staff opposition to the revised standards than were centers with $<10$ employees.

Centers that were free or state-subsidized were more likely to report being "very prepared" to make changes and were less likely to report needing additional money or staff for implementation compared with those charging \$101-\$200.99 per week for 2-5-year-old children.

\section{Meeting F\&B Standards or Best Practices}

Table 4 presents factors associated with centers' reportedly meeting selected CACFP F\&B standards/best practices. Centers in states with enhanced CACFP standards were more likely to report meeting beverage standards/best practices but not the other food standards/best practices. Centers that reported being less familiar with the updated standards (i.e., "somewhat" or "not at all/I don't know") were less likely to meet the beverage standards/best practices and the whole grain best practices than centers that were "very much" familiar with the standards.

Centers that were only "somewhat" familiar with the standards were less likely than those that were "very much" familiar with the standards to report meeting the low sugar cereal standard or to include an $\mathrm{F} / \mathrm{V}$ as a component of a snack at least 1 time/day, while centers that were "not at all/ I don't know" familiar were significantly less likely than those that were "very much" familiar with the standards to report meeting the processed meat best practices.

Notably, weekly enrollment rates were significantly associated with meeting all of the F\&B standards/best practices studied herein except for yogurt and including an F/V as a snack component, as reported by the center. Specifically, free or state-subsidized centers and those charging $\geq \$ 201$ weekly were more likely to meet specific standards/best practices compared with those charging \$101-\$200.99, while centers charging \$1-\$100.99 were less likely to meet some standards/best practices.

Although not presented in the Table, centers that were free or state-subsidized reported being less likely than those charging \$101-\$200.99 to serve at least one serving each per week of dark green leafy vegetables [adjusted odds ratio $(\mathrm{AOR})=0.48,95 \%$ confidence interval $(C I)=0.29,0.80]$, red or orange vegetables $(A O R=0.27$,
$95 \% \mathrm{CI}=0.15-0.48)$, starchy vegetables $(\mathrm{AOR}=0.37$, $95 \% \mathrm{CI}=0.22-0.62)$, and other vegetables $(\mathrm{AOR}=0.41$, $95 \% \mathrm{CI}=0.21-0.80)$.

\section{Discussion and Conclusions}

To our knowledge, this was the first nationwide survey of nonhome-based, CACFP-participating ECE centers. The study goal was to provide a baseline understanding of the centers' awareness of and reported readiness to implement the updated standards, and to understand their F\&B practices. It was encouraging that most of the centers reported being "very much" familiar with the updated standards before their effective date, being "very prepared" to make changes, and to have begun implementation at the time of survey. Equally encouraging were the high rates of centerreported practices for children ages 2-5 years that met USDA's standards or best practices.

Prior studies reported high rates of CACFP-participating center compliance with nutrition standards, ${ }^{9,11-14,16,17}$ which could be partly attributable to extensive training provided about the program from corporate headquarters, the Head Start program, and/or from Federal Food Program sponsors. Given that nearly $69 \%$ of our survey respondents fell into one of these categories, high levels of reported compliance are not surprising; however, even so, only $64 \%$ of these centers reported being "very much" familiar with the updated standards. In addition, approximately one-half of respondents indicated needing additional time, staff, or money to implement the updated standards.

Prior studies called for ongoing and continued training of ECE providers on regulatory compliance and supportive nutrition practices. Findings reported herein support this recommendation, given that center readiness for implementation was heavily influenced by reported familiarity with the standards (Tables 3-4). Ensuring that all centers are not only familiar with the updated standards but also properly trained on what meets the standards and how to best implement them will be important. Future research also should assess the best methods and formats for the trainings and related materials and priority topic areas.

Two prior CACFP-related studies examined the whole grain changes in the proposed and eventually promulgated updated CACFP standards. Schwartz et al. found that centers thought they were serving $100 \%$ whole grain bread because the bread was not white in color ${ }^{18}$ and Dave and Cullen found centers were only partially meeting the $100 \%$ whole grain requirement. ${ }^{19}$ In the current study, most centers reported serving $100 \%$ whole grain products based primarily on $(>80 \%)$ reading the nutrition label (data not shown). Our results, when informed by prior work, suggest there may be training opportunities in label reading for those who are responsible for planning, purchasing, and preparing/cooking meals and snacks at ECE centers. ${ }^{18,19}$

Schwartz et al. also examined whether policy changes related to offering a greater variety of $F \& V$ would increase 
$\mathrm{F} \& \mathrm{~V}$ consumption as seen in prior state work. ${ }^{18}$ While our study did not involve direct observation, the majority of centers reported serving a variety of vegetables from the USDA's vegetable groups. This is likely underreported given that our list of vegetables to select from was small to minimize respondent burden.

Although we attempted to follow survey design and webbased survey best practices, ${ }^{40}$ the study was subject to several limitations. First, we had to develop a national sample frame of nonhome-based, CACFP-participating ECE centers. Child care homes were excluded due to resource limitations and challenges with obtaining home-based CACFP provider lists, given that such sites are infrequently $(10 \%)$ found on state or federal child care registries. ${ }^{21}$ Future research should include home-based centers.

Also, the final frame and respondent sample did not include centers from Louisiana or Maine (where center lists were not available) and Arkansas (no respondents). Second, while our overall completion response rate was low (25\%), it is consistent with similar CACFP and ECE center provider surveys ${ }^{12,16,31-33}$ and with survey research literature on declining web-based survey response rates. ${ }^{34,35}$ Unfortunately, we did not have the resources to incentivize each respondent, which could have increased response rates, and in the future we plan to send an advance message before fielding the survey. However, weighted community characteristics of responding centers were quite comparable with those of the full sample. Third, this was a cross-sectional survey and, therefore, the results reported herein reflect associations rather than causation.

Fourth, this was a descriptive, exploratory study that examined a wide range of possible associations, so there is a significant possibility that some associations found herein are spurious type I errors. Future studies should try to confirm specific hypotheses based on this work. Fifth, the survey was based on self-reported responses and, therefore, may overstate actual practices. Resources permitting, future studies would benefit from objective data collection as well (including menu and food purchasing receipt audits). Sixth, to maintain a survey length that centers would complete with minimal burden, our lists of F\&V and yogurt options were limited. Future studies should include an expanded list of items to better understand the degree of compliance. Finally, the survey was only administered in the English language, making it possible that some nonresponse was language related.

In summary, this was the first survey of nonhome-based, CACFP-participating ECE centers nationwide. The findings presented herein provide encouraging insights as to center-reported readiness for implementing the updated federal standards and highlight opportunities for education and training, particularly of smaller, independent centers that are not corporate owned, Head Start affiliated, or with a Federal Food Program sponsor. During this transition year, ${ }^{6}$ it will be important to provide centers with the necessary training and technical assistance to ensure that all centers can comply with the federal regulations.

\section{Acknowledgments}

Funding for this study was provided by the Robert Wood Johnson Foundation (grant \#73758) for the Policies for Action Children's Healthy Weight Hub. Access to the REDCap data system was provided by the University of Illinois at Chicago Center for Clinical and Translational Science (grant \#UL1TR002003). The authors gratefully acknowledge the following experts for their input into the survey content: Geri Henchy, Tracy Fox, Lorrene Ritchie, Lindsey Turner, Rachel Tabak, and Sara MorelandRussell. They also thank Kush Patel for the research assistance provided with the data analysis and Sabrina Young, Alejandro Hughes, Joseph Huang, Anmol Sanghera, Jamie-Leigh Danemayer, and Yadira Herrera for their help in developing the national sample frame and/or fielding the survey.

Finally, the authors specifically thank all the providers that took the time to participate in this project by completing the survey. Portions of the results presented herein were initially presented at the American Public Health Association annual meeting in Atlanta, Georgia, in November 2017 and at the National Anti-Hunger Conference in Washington, DC, in February 2018.

\section{Author Disclosure Statement}

No competing financial interests exist.

\section{References}

1. U.S. Department of Agriculture Food and Nutrition Service. Child and Adult Care Food Program. 2016. Available at www.fns .usda.gov/cacfp/child-and-adult-care-food-program Last accessed May 20, 2017.

2. Russo R, Henchy G. Child and Adult Care Food Program: Participation trends 2017. Washington, DC: Food Research \& Action Center. Available at http://frac.org/wp-content/uploads/CACFPparticipation-trends-2017.pdf Last accessed May 20, 2017.

3. U.S. Department of Agriculture. Child nutrition programs: Income eligibility guidelines. Fed Reg 2017;82:17182-17184.

4. U.S. Department of Agriculture. Child and Adult Care Food Program: Meal pattern revisions related to the Healthy, Hunger-Free Kids Act of 2010. Final rule. Fed Reg 2016;81:24347-24383.

5. Skinner JD, Carruth BR, Wendy B, et al. Children's food preferences: A longitudinal analysis. J Acad Nutr Diet 2002;102:1638-1647.

6. U.S. Department of Agriculture. Transition period for the updated Child and Adult Care Food Program meal program and the updated National School Lunch Program and School Breakfast Program infants and preschool meal patterns. 2017. Available at https://www .fns.usda.gov/transition-period-updated-cacfp-infant-preschoolmeal-patterns Last accessed May 20, 2017.

7. Lessard L, Williams Leng S, Brennan R. Consistency of compliance with nutrition-related regulations among Delaware child care centers. Child Obes 2013;9:233-239.

8. Sweitzer SJ, Briley ME, Robert-Gray C. Do sack lunches provided by parents meet the nutritional needs of young children who attend child care? J Am Diet Assoc 2009;109:141-144. 
9. Heflin C, Arteaga I, Gable S. The Child and Adult Care Food Program and food insecurity. Soc Serv Rev 2015;89:77-98.

10. Ritchie LD, Yoshida S, Sharma S, et al. Drinking water in California child care sites before and after 2011-2012 beverage policy. Prev Chronic Dis 2015;12:E89.

11. Korenman S, Abner KS, Kaestner R, et al. The Child and Adult Care Food Program and the nutrition of preschoolers. Early Child Res $Q$ 2013;28:325-336.

12. Ritchie LD, Boyle M, Chandran K, et al. Participation in the Child and Adult Care Food Program is associated with more nutritious foods and beverages in child care. Child Obes 2012;8:224-229.

13. Bruening KS, Gilbride JA, Passannante MR, et al. Dietary intake and health outcomes among young children attending 2 urban daycare centers. J Am Diet Assoc 1999;99:1529-1535.

14. Blaine RE, Davison KK, Hesketh $\mathrm{K}$, et al. Child care provider adherence to infant and toddler feeding recommendations: Findings from the baby nutrition and physical activity self-assessment for child care (baby NAP SACC) study. Child Obes 2015;11:304-313.

15. Liu ST, Graffagino CL, Leser KA, et al. Obesity prevention practices and policies in child care settings enrolled and not enrolled in the Child and Adult Care Food Program. Matern Child Health $J$ 2016;20:1933-1939.

16. Ritchie LD, Sharma S, Gildengorin G, et al. Policy improves what beverages are served to young children in child care. J Acad Nutr Diet 2015;115:724-730.

17. Sigman-Grant M, Christiansen E, Fernandez G, et al. Child care provider training and a supportive feeding environment in child care settings in 4 states, 2003. Prev Chronic Dis 2011;8:A113.

18. Schwartz MB, Henderson KE, Grode G, et al. Comparing current practice to recommendations for the Child and Adult Care Food Program. Child Obes 2015;11:491-498.

19. Dave JM, Cullen KW. Foods served in child care facilities participating in the Child and Adult Care Food Program: Menu match and agreement with the new meal patterns and best practices. $J$ Nutr Educ Behav 2018;50:582-588.

20. Glanz K, Rimer BK, Lewis FM. Health Behavior and Health Education: Theory, Research, and Practice, 3rd ed. Jossey-Bass: San Francisco, CA, 2002.

21. National Survey of Early Care and Education Project Team. Characteristics of home-based early care and education providers: Initial findings from the national survey of early care and education. Vol 2016-13. Washington, DC: Office of Planning, Research and Evaluation, Administration for Children and Families, U.S. Department of Health and Human Services. 2016. Available at https:/www.acf.hhs.gov/sites/default/files/opre/characteristics of_home_based_early_care_and_education_toopre_032416.pdf Last accessed May 20, 2017.

22. U.S. Department of Agriculture Food and Nutrition Service. CACFP total outlets as of March 2016. National Data Bank Version 8.2 Public Use. Washington, DC, 2016.

23. Kim S, Adamson KC, Balfanz DR, et al. Development of the community healthy living index: A tool to foster healthy environments for the prevention of obesity and chronic disease. Prev Med 2010;50:S80-S85.

24. Wolfenden L, Jones J, Williams CM, et al. Strategies to improve the implementation of healthy eating, physical activity and obesity prevention policies, practices or programmes within childcare services. Cochrane Database Syst Rev 2016;10:CD011779.

25. Lyn R, Evers S, Davis J, et al. Barriers and supports to implementing a nutrition and physical activity intervention in child care: Directors' perspectives. J Nutr Educ Behav 2014;46:171-180.
26. Child Care Aware of America. Parents and the high cost of childcare: 2017. Available at https://usa.childcareaware.org/advocacypublic-policy/resources/research/costofcare Last accessed May 20, 2017.

27. Presser S. Methods for Testing and Evaluating Survey Questionnaires. Wiley-Interscience: Hoboken, NJ, 2004.

28. Willis G. Cognitive interviewing. Thousand Oaks, CA, 2005: Available at http://methods.sagepub.com/book/cognitive-interviewing Last accessed February 23, 2018.

29. UIC Center for Clinical Translational Science. REDCap: Research electronic data capture. UIC Center for Clinical and Translational Science, 2018. Available at www.ccts.uic.edu/content/redcapresearch-electronic-data-capture Last accessed August 30, 2018.

30. American Association for Public Opinion Research. Response rates-an overview. 2018. Available at www.aapor.org/EducationResources/For-Researchers/Poll-Survey-FAQ/Response-Rates-AnOverview.aspx Last accessed February 20, 2018.

31. Lee D, Gurzo K, Yoshida S, et al. Compliance with the new 2017 Child and Adult Care Food Program (CACFP) meal patterns prior to implementation. Child Obes (In Press).

32. Tovar A, Risica P, Mena N, et al. An assessment of nutrition practices and attitudes in family child-care homes: Implications for policy implementation. Prev Chronic Dis 2015;12:E88.

33. Erinosho T, Vaughn A, Hales D, et al. Participation in the Child and Adult Care Food Program is associated with healthier nutrition environments at family child care homes in Mississippi. $J$ Nutr Educ Behav 2018;50:441-450.

34. Fan W, Yan Z. Factors affecting response rates of the web survey: A systematic review. Comput Hum Behav 2010;26:132-139.

35. Sauermann H, Roach $M$. Increasing web survey response rates in innovation research: An experimental study of static and dynamic contact design features. Res Policy 2013;42:273-286.

36. U.S. Census Bureau. 2011-2015 ACS 5-year estimates. 2016. Available at www2.census.gov/programs-surveys/acs/summary file/2015/data/5_year_by_state Last accessed March 20, 2017.

37. Food Research \& Action Center. CACFP enhanced nutrition standards nutrition and wellness state agency survey results. Available at http://frac.org/wp-content/uploads/cacfp-enhanced-nutritionstandards.pdf Last accessed February 1, 2018.

38. U.S. Census Bureau. 2010 census summary file 1. 2011. Available at https://factfinder.census.gov/faces/nav/jsf/pages/index.xhtml Last accessed October 15, 2017.

39. U.S. Census Bureau. Census regions and divisions. Available at https://www2.census.gov/geo/pdfs/maps-data/maps/reference/us_ regdiv.pdf Last accessed May 20, 2017.

40. Dillman DA. Mail and Internet Surveys: The Tailored Design Method, 2nd ed. John Wiley \& Sons, Inc.: New York, NY, 2007.

Address correspondence to: Jamie F. Chriqui, PhD, MHS Division of Health Policy and Administration and Institute for Health Research and Policy School of Public Health University of Illinois at Chicago 1747 W. Roosevelt Road, M/C 275 Chicago, IL 60608

E-mail: jchriqui@uic.edu 